\title{
Bilateral Posterior and Lateral Ponticles Resulting In the Formation of Vertebral Artery Canal for the Atlas: Case Report
}

\author{
Vanitha ${ }^{1}$, Chandrika G Teli ${ }^{2}$, H. S. Kadlimatti ${ }^{3}$ \\ ${ }^{1,2,3}$ (Department of Anatomy, ESIC Medical College Gulbarga/ Rajiv Gandhi university of health \\ Sciences, Karnataka, India)
}

\begin{abstract}
Atlas first cervical vertebra having no spine and body differs from other vertebra. Contains two archs anterior and posterior. Posterior arch contains groove for vertebral artery. During routine osteology classes for undergraduate medical students, we observed presence of bilateral posterior and lateral ponticles which are forming canal for vertebral artery on behind and lateral to lateral mass of atlas. Present case report is very rare anomaly which may lead to stenosis of vertebral artery and may be useful for orthopaedics during surgical manipulation of cervical spine.
\end{abstract}

Keywords: Arcuate foramina, atlas vertebra, ponticuli, posterior arch.

\section{Introduction}

First cervical vertebra called as atlas, which support the globe of the head. The name of the atlas derived from a deity of Greek mythology called atlas. It is ring shaped having two arch anterior and posterior. Atlas differes from other vertebra without body and spine. Contains weight bearing two lateal mass with articular facets. Posterior arch forms $3 / 5^{\text {th }}$ of circumference of atlantal ring, having groove called as sulcus arteriae vertebralis which transmits vertebral artery and first cervical nerve. Rarely this groove may be converted into foramen by complete posterior ponticles connecting the superior articular facet to posterior arch. This foramina called by different names as saggitale foramen and atlantal posterior foramen, arcuate foramen,a variant of Kimmerle's anomaly, canalis vertbralis, retroarticular vertebral artery ring, arcuate foramen ,retroarticular canal, and retrocondilar vertebral artery ring, ponticulus posticus. Some times very rarely can see lateral ponticles.These spicule extend from the superior edge of the lateral mass of atlas to posterior root of the transverse process. Presences of bilateral posterior and lateral ponticles are very rare.In this case we are reporting presence of both ponticles bilaterally resulting canal for vertebarl artery.

\section{Case Report}

During osteology demonstration classes for undergraduate medical students, we observed that presence of bilateral posterior ponticles projecting from the posterior edge of lateral mass to join the posterior margin of groove of vertebral artery of atlas forming the arcuate foramen bilaterally [fig.1]. We also noticed projecting bilateral lateral ponticle from the lateral edge of lateral mass and from the root of transverse process but both spicule failed to fuse forming incomplete lateral foramen.Thus both these ponticles forming canal behind and lateral to the lateral mass for vertebral artery bilaterally[fig 2].

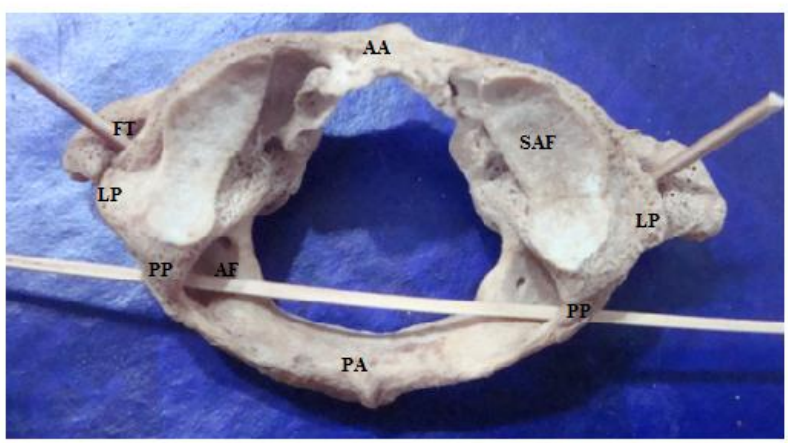

Figure 1: showing arcuate foramen bilaterally $[\mathrm{AF}]$ and lateral ponticles $[\mathrm{LP}]$ both the sides ,posterior ponticles [PP],superior articular facet[SAF],posterior arch $[\mathrm{PA}]$,anterior arch [AA],foramina transrersarium[FT]. 


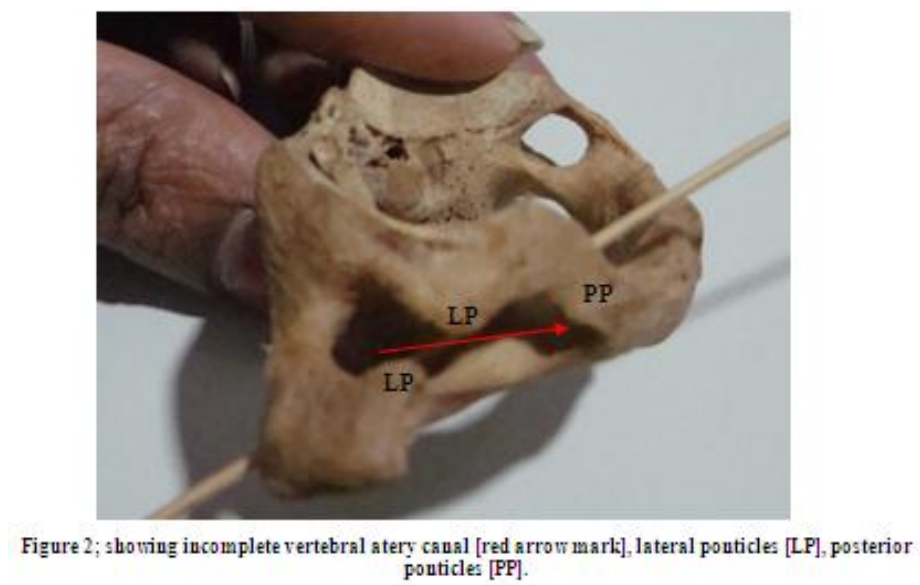

\section{Discussion}

In this case we observed a very rare anomaly presence of bilateral canal for vertebral artery. Tubbs et al., noticed presence of unilateral vertebral canal ${ }^{1}$. Rekha et al., noticed out of 200 macerated atlas, posterior ponticuli in 62(31\%), lateral in 13(6.5\%) and posterolateral in 5(2.5), complete ponticuli in 9(4.5\%), incomplete in $69(34.5 \%)$ and bilateral $34(17 \%)$, unilateral in $46(28 \%)$, right sided in $24(12 \%)$ and left sided in $22(11 \%)$. Incidences of posterior incomplete unilateral ponticuli were higher in their study and posterior complete ponticuli were more compared to lateral ${ }^{2}$. Radiographic study reveals about presence of ponticulus posticus bilateral complete in $34.5 \%$, bilateral incomplete in $11.6 \%$,one complete and one incomplete $09.5 \%$, unilateral complete in $24.8 \%$, unilateral incomplete in $19.6 \%$ and complaints which exhibits in ponticulus posticus ,backpain( dorsal ,lumbar,sacral)in 36\%,headache,vertigo,diplopia in $2.9 \%$, neck, brachial symptoms in $23.7 \%$, hip,leg pain $08.2 \%$,tension, hypeactivity,insomnia , high blood pressure in $04.3 \%$,respiratory illness in $01.7 \%{ }^{3}$. Cushing $\mathrm{K} \mathrm{E}^{4}$ and Taitz et al., ${ }^{5}$ concluded , the lateral and posterior ponticles may be remnants of proatlas, the so called occipital vertebra. Mitchell ${ }^{6}$ and Romanus et al., ${ }^{7}$ suggested that they represent ossified primitive ligaments or parts of the posterior atlanto-occipital ligaments. The lateral ponticuli may represent the rudimentary transverse process of the proatlas ${ }^{8}$. Taitz and Nathan ${ }^{5}$ stated that the foramen arcuale might be considered as accessory transverse foramen. Origin of the bony bridge is an issue, previous studies have suggested it may be a product of congenital development(Allen ${ }^{9}, 1879$;Cleland ${ }^{10}, 1960$; VonTorklus et al., ${ }^{11}$ 1975), a genetic trait(Selby et al., ${ }^{12}$ ) , an ossification due to age (Pyo\&Lowman ${ }^{13}, 1959$; Breathnach ${ }^{14}, 1965$;White \&Panjabi ${ }^{15}, 1978$ ), or the result of external mechanical factors(Taitz \&Nathan ${ }^{5}$,1986). Foramen arcuale is associated with Barre-Lieou syndrome, which represents symptoms of headache, retro-orbital pain, vasomotor disturbance of the face and recurrent disturbances of vision, swallowing and phonation due to alteration of blood flow within the vertebral arteries and an associated disturbance of periarterial disturbance of periarterial nerve plexus. More than $50 \%$ of head rotation occurs at the atlantoaxial joint, the vertebral artery is most vulnerable to compression and stretching at this level; thus additional compression /tethering of this vessel by a foramen arcuale may compound its predisposition to injury ${ }^{16}$.

\section{Conclusion}

Vertebral artery is vulnerable to compression during extreme rotations of the head and neck. This situation may be aggravated by the presence of this canal for vertebral artery resulting in stenosis and compromised blood flow. It can also taken count by the orthopaedic surgeons during a surgical manipulation of the cervical spine. This report may also be useful for neurosurgeons, radiologists, anthropologists.

\section{References}

[1]. R.Shane Tubbs: Simultaneous lateal and posterior ponticles resulting in the formation of vertebral artery tunnel of the atlas: case report and review of the literature: folia neuropathologica; 45(1):43-46.2007.

[2]. Rekha B S: Study of ponticuli in human atlas vertebrae: journal of evolution of medical and dental sciences vol.2 : issue 45, pp.8849-8855.2013

[3]. Roy W.Sweat: The ponticulus posticus; September/October 1987: 95-97.

[4]. Cushing K E: Tethering of vertebral artery in the congenital arcuate foramen of the atlas vertebra: possible cause of vertebral artery dissection in children. Dev Med child neurol 2001; 43:491-496.

[5]. Taitz c, Nathan H.Some observations on the posterior and lateal bridge of the atlas. Acta Anat (Basel) 1986; 127:212-217.

[6]. Mitchell J; the incidence and dimensions of the retroarticular canal of the atlas vertebra. Acta anat (Basel) 1998; 163:113-120.

[7]. Romanus T, Tovi A: a variation of the atlas .Roentgenolgic incidence of a bridge over the groove on the atlas for the vertebral artery.Acta Radiol Diagn (Stockh) 1964; 2:289-297.

[8]. Buna M, Coghlan: ponticles of the atlas: review and clinical perspective. j Manipulative physiol Ther 1984; 7; 261-266. 
[9]. Allen, W. On the varieties of the atlas in the human subject, and the homologies of its transverse processes. J. Anat., 14:18-28, 1879.

[10]. Cleland, M. On the serial homologies of the articular surfaces of the mammalian atlas, axis and occipital bone. Proc.R. Soc. Edinb., $2: 221,1860$.

[11]. Von Torklus, D.; Rklus, D. \& Gehle, W. Die Obere Halswribelsaüle. Stuttgart, Thieme, 1975. Vol. 2.

[12]. Selby, S.; Garn, S. M. \& Kanareff, V. The incidence and familial nature of a bony bridge on the first cervical vertebra. Am. J. Phys. Anthropol., 13(1):129-41, 1955.

[13]. Pyo, J. \& Lowman, R. M. The ponticulus posticus of the first cervical vertebra. Radiology, 72(6):850-4, 1959.

[14]. Breathnach, A. S. Frazer's Anatomy of the Human Skeleton.6th ed. London, J. \& A. Churchill, 1965. p. 29.

[15]. White, A. A. \& Panjabi, M. M. Clinical Biomechanics of the Spine. Philadelphia, Lippincott, 1978

[16]. Limousin CA. Foramen arcuale and syndrome of Barre-Lieou. Its surgical treatment. Int Orthop. 1980; 4: 19-23. 